\title{
Beta catenin and cytokine pathway dysregulation in patients with manifestations of the "PTEN hamartoma tumor syndrome"
}

\author{
Martina Galatola ${ }^{1}$, Lorella Paparo ${ }^{1}$, Francesca Duraturo ${ }^{1}$, Mimmo Turano ${ }^{2}$, Giovanni Battista Rossi ${ }^{3}$, Paola Izzo ${ }^{1 \dagger}$ and \\ Marina De Rosa ${ }^{1 *+}$
}

\begin{abstract}
Background: The "PTEN hamartoma tumor syndrome" (PHTS) includes a group of syndromes caused by germline mutations within the tumor suppressor gene "phosphatase and tensin homolog deleted on chromosome ten" (PTEN), characterized by multiple polyps in the gastrointestinal tract and by a highly increased risk of developing malignant tumours in many tissues.

The current work clarifies the molecular basis of PHTS in three unrelated Italian patients, and sheds light on molecular pathway disregulation constitutively associated to PTEN alteration.

Methods: We performed a combination of RT-PCR, PCR, sequencing of the amplified fragments, Real Time PCR and western blot techniques.

Results: Our data provide the first evidence of $\beta$-catenin accumulation in blood cells of patients with hereditary cancer syndrome caused by germ-line PTEN alteration. In addition, for the first time we show, in all PHTS patients analysed, alterations in the expression of TNF $\alpha$, its receptors and IL-10. Importantly, the isoform of TNFRI that lacks the DEATH domain (TNFRSF1 $\beta$ ) was found to be overexpressed.

Conclusion: In light of our findings, we suggest that the PTEN pathway disregulation could determine, in nonneoplastic cells of PHTS patients, cell survival and pro-inflammatory stimulation, mediated by the expression of molecules such as $\beta$-catenin, TNF $\alpha$ and TNF $\alpha$ receptors, which could predispose these patients to the development of multiple cancers.
\end{abstract}

Keywords: PTEN hamartoma tumor syndrome, PTEN, $\beta$-catenin, TNFa receptors

\section{Background}

PTEN hamartoma tumor syndrome is the term that has recently been used to describe Cowden syndrome (CS), Bannayan-Riley-Ruvalcaba syndrome (BRRS), Proteus syndrome (PS), and Proteus-like syndrome. These disorders are all caused by mutations in the PTEN gene and are all characterized by extraintestinal manifestations in addition to intestinal polyposis. PHTS is inherited in an autosomal dominant manner, and is likely to be underdiagnosed because of its phenotypic variability, its incomplete

\footnotetext{
*Correspondence: marina.derosa@unina.it

+ Contributed equally

'Dipartimento di Biochimica e Biotecnologie Mediche and CEINGE Biotecnologie Avanzate, Università di Napoli Federico II, via S. Pansini 5 , Naples 80131, Italy

Full list of author information is available at the end of the article
}

penetrance, and the fact that many of its component features are subtle and occur in the general population [1].

CS is a rare multiple hamartoma syndrome with a reported incidence of 1 in 200,000 individuals. This syndrome is characterized by macrocephaly, mucocutaneous lesions (such as facial trichilemmoma), acral keratosis, and glycogenic acanthosis of the esophagus and papillomatous papules. It is also associated with thyroid, breast, and endometrial manifestations, including cancer in all of these areas. Renal cancer has also been associated with CS; the risk of developing gastrointestinal carcinoma in CS is of about 13\% [2]. The BRRS is a congenital disorder characterized by macrocephaly, intestinal hamartomatous polyposis, lipomas, and pigmentated macules of the glans penis. It is recommended that individuals with BRRS 
should be considered at risk for malignancy, as with CS. PS is a complex, highly variable disorder involving congenital malformations and hamartomatous overgrowth of multiple tissues.

The diagnosis of PHTS is made only when a PTEN mutation is identified. Approximately $85 \%$ of individuals who meet the diagnostic criteria for CS and $65 \%$ of individuals with a clinical diagnosis of BRRS have a detectable PTEN gene mutation. Since the most serious consequences of PHTS relate to the increased risk of breast, thyroid, endometrial, and renal cancers, the most important aspect of managing individuals with a PTEN mutation is increased cancer surveillance $[3,4]$.

$P T E N$ is a 9-exon tumour suppressor gene that encodes for a 403 amino acid protein. It acts as a lipid phosphatase to negatively regulate the PI3K/AKT/mTOR Pathway $[5,6]$. Recently, nuclear compartmentalization of PTEN has been found as a key component of its tumor-suppressive activity [7]. Close to 100 different germ-line mutations of PTEN have been reported to date encompassing point, nonsense, frame shift, splice site, missense, and deletion/ insertion mutations. Most mutations occur in exon 5, but mutations in all other exons, except the first, have also been described. Around 10\% of PTEN mutations occur in the promoter region, and the role of epigenetic regulation is not well understood.

Somatic PTEN mutations have been identified in a large number of sporadic tumours such as glioblastomas, prostate cancer, melanomas, thyroid and endometrial tumours [3].

Evidence exists indicating that PTEN is a functionally haploinsufficient tumour suppressor gene [8]. Indeed, in human cancers, monoallelic mutation of PTEN without loss or mutation of the second allele is prevalent at an early stage, whereas complete loss is observed at low frequencies with the exception of advanced cancers $[9,10]$. Recent studies describe the functional relationship between mRNAs produced by the PTEN tumour suppressor gene and its pseudogene PTENP1, as well as the critical consequences of this interaction. These studies show that PTENP1 is biologically active as it can regulates cellular levels of PTEN and plays a growth-suppressive role [8].

In the current work, we present data obtained by studying three PHTS patients with a clinical diagnosis of CS (PHTS2 and PHTS3) and BRRS (PHTS1), respectively. The aim was to understand the pathogenetic mechanisms of the PTEN tumour suppressor gene alteration, and to clarify the molecular changes downstream of a PTEN alteration and constitutively associated to it.

\section{Methods}

\section{Patients}

A total of 3 unrelated patients, exhibiting hamartomatous polyposis, were referred by gastroenterologists to the laboratory, for genetic analysis. The histological aspect of the polyps was unambiguous in all cases and it is tipic of PHTS polyps. Differential diagnosis with the juvenile polyposis syndrome (JPS) was made for PHTS2 and PHTS3 patients because none of the patients showed polyps histologically characteristic of the JPS. In fact, in both patients polyps were hamartomas with glandular structures, muscle fibers and also ganglioneuromatosi elements, while Juvenile polyps show a normal epithelium with a dense stroma, an inflammatory infiltrate, and a smooth surface with dilated, mucus-filled cystic glands in the lamina propria. Muscle fibers and the proliferative characteristics of adenomas are typically not seen in juvenile polyps [11]. In addition, the PHTS2 patient showed extensive glycogenic acanthosis, that is a characteristic feature of Cowden syndrome [12], whereas, the PHTS3 patient showed horseshoe kidney. It was the combination of these elements that can be found in Cowden syndrome to suggest the diagnosis. Clinical phenotype, family history and molecular characterization of each patient are reported in Table 1.

Blood samples from healthy subjects were collected from the same hospital as the PHTS patients.

Samples from all families that participated in the study were collected after being granted authorization from the "Comitato etico per le attività Biomediche - Carlo Romano" of the University of Naples Federico II, with protocol number $120 / 10$. Such authorization is given only once the study has received ethical approval, and participants' informed and written consent has been obtained.

\section{Molecular analysis of the PTEN messenger RT-PCR of PTEN full length coding region in PHTS patients} Cells from from $3 \mathrm{ml}$ of peripheral blood of these three PHTS patients were pelleted, total RNA was extracted using Trizol reagent (invitrogen, Life Technologies, Ca, USA), and cDNA was synthesized using $1 \mu \mathrm{g}$ of total RNA, $500 \mathrm{ng}$ of random hexamers and $1 \mu$ l Superscript III reverse transcriptase (INVITROGEN), in the presence of $4 \mu \mathrm{l} 5 \mathrm{X}$ RT buffer, $1 \mu \mathrm{l}$ DTT $(0.1 \mathrm{M})$ and $1 \mathrm{mM}$ dNTPs. The reaction was run for $50 \mathrm{mins}$ at $42^{\circ} \mathrm{C}$ in a $20 \mu \mathrm{l}$ reaction volume, heated to $70^{\circ} \mathrm{C}$ for 15 mins and quick chilled on ice. Next, $1 \mu$ l of the cDNA was amplified by PCR using the following couple of oligonucleotides:

PTEN-5'UTR-1FP: TTCCATCCTGCAGAAGAAGC [NM_000314.4]; start: +950;

PTEN-3'UTR-1RP: TCTGAGCATTCCCTCCATTC [NM_000314.4]; start: + 2765.

The amplification reaction produced a fragment of 1815 bp of molecular weight. The PCR products were analysed on a $1 \%$ agarose gel in a trisacetic acid (TAE)EDTA standard buffer, and visualized by ethidium bromide staining. 
Table 1 Clinical phenotype and molecular characterization of Italian PHTS patients studied

\begin{tabular}{|c|c|c|c|c|c|}
\hline Patient & S/ & $\begin{array}{l}\text { Age of } \\
\text { diagnosis }\end{array}$ & Mutation & Clinical manifestations & Affected relatives \\
\hline PHTS1 & $\mathrm{F}$ & 53 yrs & $\begin{array}{l}\mathrm{C} .406 \\
\mathrm{~T} \rightarrow \mathrm{Cp} . \\
\mathrm{C} 136 \mathrm{R}\end{array}$ & $\begin{array}{l}\text { BRRS: macrocephaly, brain asymmetry, arteriovenous malformations, } \\
\text { glycogenic acanthosis, hamartomatous gastric polyps, colon cancer, } \\
\text { penis macules, keratosis of the hands and feet }\end{array}$ & $\begin{array}{c}\text { Father and one brother died of colon } \\
\text { cancer; they both showed penis } \\
\text { macules. }\end{array}$ \\
\hline PHTS2 & $\mathrm{S}$ & 45 yrs & $\downarrow \mathrm{mRNA}$ & $\begin{array}{l}\text { CS: hamartomatous gastric Cowden polyps, colon cancer, glycogenic } \\
\text { acanthosis, keratosis of the hands and feet, a few freckles on penis }\end{array}$ & - \\
\hline PHTS3 & S & 54 yrs & $\downarrow \mathrm{mRNA}$ & $\begin{array}{c}\text { CS: hamartomatous colonic Cowden polyps, colon cancer, horseshoe } \\
\text { kidney. }\end{array}$ & - \\
\hline
\end{tabular}

PHTS1, PHTS2 and PHTS3: patients affected by PHTS syndrome; F: familial cases; S: sporadic cases

\section{Sequence analysis of PTEN messenger}

Sequence analysis of the PTEN full length coding region was performed on amplified fragments from the cDNA of all three patients, using the following primer pairs:

PTEN-5'UTR2-FP: GCAGCTTCTGCCATCTCTCT; [NM_000314.4]; start: +980;

PTEN-7cRP: TCACCACACACAGGTAACGG; [NM 000314.4]; start: +1786;

PTEN 5cFP: TTGAAGACCATAACCCACCAC; [NM 000314.4]; start: +1300;

PTEN-8cRP: CCTTGTCATTATCTGCACGC; [NM_ 000314.4]; start: +1971;

PTEN-7cFP: CGACGGGAAGACAAGTTCAT; [NM_000314.4]; start: +1728;

PTEN-3'UTR2-RP: TAAAACGGGAAAGTGCCATC; [NM_000314.4]; start: +2530 .

The analysis was performed in a 3100 Genetic Analyzer (Applied Biosystems, Foster City, CA, USA). For nucleotide numbering, the first A of the initiator ATG codon is nucleotide +1 of the PTEN mRNA sequence [GenBank Accession number NM_000314.4]. All oligonucleotides were obtained with primer-BLAST Software http://www. ncbi.nlm.nih.gov/tools/primer-blast/.

\section{Real Time RT-PCR quantification analysis}

Real Time PCR quantification analysis was performed for the PTEN messenger. The relative expression was calculated with the comparative $\mathrm{Ct}$ method. Patient-numbering corresponds to that adopted in Table 1. Three ml of peripheral blood cells from PHTS patients and healthy subjects were pelleted after erythrocytes lysis and resuspended in a Trizol reagent. In order to better normalize the healthy values, we used four blood mixes as controls, each containing five samples collected from healthy subjects, for a total of twenty controls (data not shown). In order to allow accurate evaluation of interindividual variability in expression, we also separately analysed 20 samples, collected from healty subjects. PHTS1, PHTS2 and PHTS3 are the three patients affected by PHTS syndrome, as reported in Table 1.

The PTEN mRNA quantification was carried out by amplifying fragments spanning the junctions between exons 5-6, compared to the glucuronidase transcript fragment, using the following oligonucleotides:
PTEN-5c2FP: ATGGGGAAGTAAGGACCAGAG; [NM_000314.4]; start: +1495;

PTEN-6cRP: TCTTGTGAAACAACAGTGCCA; [NM_000314.4]; start: +1623 .

The quantitative Real Time assays were performed using the iCycler iQ Real Time Detection System (BIO-RAD). Amplification was carried out within a total volume of 15 $\mu$ containing the SYBR Green PCR Master Mix 1X (BIORAD), using 20 ng of cDNA. The Real Time PCR reaction was optimized according to the manufacturer's instructions but scaled down to $15 \mu \mathrm{l}$ per reaction. The PCR conditions were standard and all reagents were contained in the standard iQ ${ }^{\mathrm{TM}}$ SYBR Green Supermix (BIORAD). The reaction protocol consisted in an initial predenaturation step at $95^{\circ} \mathrm{C}$ for 3 mins followed by 40 two-step cycles at $95^{\circ} \mathrm{C}$ for $15 \mathrm{~s}$ and $60^{\circ} \mathrm{C}$ for $1 \mathrm{~min}$.

At the end of the PCR, the temperature was increased from 55 to $95^{\circ} \mathrm{C}$ at a rate of $3^{\circ} \mathrm{C} / \mathrm{min}$, and the fluorescence was measured every $10 \mathrm{~s}$ to construct the melting curve.

A nontemplate control was run for each assay, and all determinations were performed in triplicate to ensure reproducibility. Synthesis of the expected PCR product was confirmed by melting curve analysis. Oligonucleotides yielding 100-150 bp-long PCR products at an annealing temperature of $60^{\circ} \mathrm{C}$ were obtained with primer-BLAST Software http://www.ncbi.nlm.nih.gov/ tools/primer-blast/.

\section{Molecolar analysis of PTEN gene and PTENP1 pseudogene Genomic PCR and sequencing}

Cells from $3 \mathrm{ml}$ of peripheral blood of PHTS patients and healty controls were pelleted and genomic DNA was extracted using Nucleon BACC2 Kit (Amersham; Biosciences)

Genomic PCR and sequencing of exon 5 was performed for PHTS1 patient, using oligonucleotides complementary to intronic neighboring boundary regions of the exon

(PTENg5FP: TGTTAAGTTTGTATGCAACATTTCT; [NC_ 000010.10] start: 89692673;

PTENg5RP: AACCCAAAATCTGTTTTCCA; [NC_ 000010.10] start: 89693081), in order to distinguish the gene sequence from the pseudogene sequence. The 
GenBank Accession number of PTEN genomic sequence is: NC_000010.10.

Mutational analysis of PTEN promoter region, from bp -1398 to bp +1 , was performed by PCR and sequencing. This region was amplified into two overlapping fragments of 663 and 789 bp in molecular weight, respectively, using the following primer pairs:

PTENp-FP: GTTTCTCGCCTCCTCTTCGT; [NC_ 000010.10] start: 89623575;

PTENp-RP: ATGGCTGTCATGTCTGGGA; [NC_ 000010.10] start: 89624237;

PTENp2-FP CTACACTGAGCAGCGTGGTC: [NC 000010.10] start: 89622825;

PTENp2-RP GGCTGCACGGTTAGAAAAGA; [NC_ 000010.10] start: 89623613 .

\section{Gene copy number quantification of PTEN gene and} PTENP1 pseudogene

For the genomic quantification of PTEN gene and PTENP1 pseudogene, specific amplified fragments were compared to a fragment of the exon 15 MUTYH gene. For PTEN specific quantification, two short fragments, one inside intron 9 and the other at the boundaries of exon 5 and IVS5, were amplified, using the following primer pairs:

PTEN-5c2FP: ATGGGGAAGTAAGGACCAGAG; [NM_000314.4]; start: 1495;

PTENg5RP: AACCCAAAATCTGTTTTCCA; [NC_ 000010.10] start: 89693081;

PTEN-IVS9-FP:AGGCCTCTTAAAGAT-

CATGTTTGT; [NC_000010.10] start: 89724893;

PTEN-IVS9-RP:AGAAAATTTAAAATGAAAACCCACA; [NC_ 000010.10] start: 89725035.

These oligonucleotides don't recognize the PTENP1 sequence, whereas for specific amplification of the 3'UTR of PTENP1, the primers described by Poliseno et al. [8] were used. $\mathrm{H} 1, \mathrm{H} 2$ and $\mathrm{H} 3$ are three healthy subjects supposedly not deleted for the target genes.

\section{Molecular alterations of PI3K/akt and WNT pathways associated to PHTS syndrome \\ Western blot assay of $\beta$-catenin protein}

Total proteins were extracted from $3 \mathrm{ml}$ of peripheral blood cells (about $5-7 \times 10^{3} / \mathrm{mL}$ cells) using Trizol reagent (invitrogen, Life Technologies, Ca, USA) following the manufacturer's instructions; concentrations were determined by using a protein assay kit adopting bovine serum albumin standards, according to the manufacturer's instructions (Bio-Rad Laboratories, Hercules, CA, USA). A total of $50 \mu \mathrm{g}$ protein was separated by SDS-polyacrylamide gel electrophoresis and blots were prepared on a nitrocellulose membrane Amersham Hybond-ECL (Amersham, GE healthcare, USA). The primary antibodies against $\beta$-catenin (amino-terminal and phospho beta catenin-S552 antigen) were from Cell Signaling technology (Beverly, MA, USA). The antibody against actin was from Santa Cruz (Santa Cruz, CA, USA). The membrane was probed with a secondary antibody against peroxidase-conjugated rabbit and goat immunoglobulin $\mathrm{G}$, and immunoreactive bands were detected using the enhanced chemiluminescence HRP Substrate Immobilon Western, Millipore (Millipore Corporation, Billerica, USA). $\mathrm{H}_{1-5}, \mathrm{H}_{6-10}, \mathrm{H}_{11-15}, \mathrm{H}_{15-20}$ were mixes of healthy subjects, performed as described before. PHTS1, PHTS2 and PHTS3 were the patients affected by PHTS syndrome, as reported in Table 1.

\section{Real Time PCR quantification analysis of COX2, CCND1, $C M Y C$, and APC messengers}

Relative expression was calculated with the comparative $\mathrm{Ct}$ method and normalised against the Ct of Glucuronidase (GUS) messenger. The quantitative RNA Real Time assays were performed as described before. $\mathrm{H}_{1-5}, \mathrm{H}_{6-10}$, $\mathrm{H}_{11-15}, \mathrm{H}_{15-20}$ were mixes of healthy subjects. $\mathrm{H}_{\mathrm{m}}$ was the mean value between all healthy samples used as calibrator to measure the relative expression. PHTS1, PHTS2 and PHTS3 were the three patients affected by PHTS syndrome, as reported in Table 1.

\section{Cytokine disregulation on peripheral blood cells of PHTS patients}

Real Time PCR quantification analysis of ILI0 and TNFa mRNA

Messenger quantification was performed for IL10 and TNFa and normalised against the Ct of Glucuronidase (GUS) messenger. The assay was performed as described before.

Western blot assay of TNFRI and TNFRII proteins

Primary antibodies against TNFRI and TNFRII were from R\&D System (R\&D System, Minneapolis, USA). The antibody against actin was from Santa Cruz (Santa Cruz, CA, USA). Secondary antibodies were against peroxidase-conjugated goat and mouse immunoglobulin G. The assay was performed as described before.

$\mathrm{H}_{1-5}, \mathrm{H}_{6-10}, \mathrm{H}_{11-15}, \mathrm{H}_{15-20}$ were mixes of healthy subjects, performed as before. PHTS1, PHTS2 and PHTS3 were the three patients affected by PHTS syndrome, as reported in Table 1 .

\section{RT-PCR and sequencing of TNFRIA $\beta$}

Messenger expression of the beta isoform of TNFRIA was analysed by RT-PCR and sequencing. One $\mu \mathrm{l}$ of the cDNA syntetized from RNA of each PHTS patient was amplified using the following couple of oligonucleotides:

TNFRI-5cFP: AAACAGAACACCGTGTGCAC;

TNFRI-6BcRP: CTTGAATCTGGGAGGCAGAG.

Sequence analysis was performed using the same primer pairs, as previously described. The GeneBank accession number of TNFR1A $\beta$ is: EU927389.1. 


\section{Statistical analysis}

All statistical analyses were computed using Prism software. The unpaired two-tailed $t$ test with confident intervals of $99 \%$ was calculated. A value of $p<0.005$ was considered statistically significant.

\section{Results \\ Molecular analysis of the PTEN gene at DNA and RNA level}

We performed mutational analysis of the PTEN gene, setting up a combination of $\mathrm{RT}-\mathrm{PCR}$ reaction of the whole cDNA, PCR of genomic region, including the promoter region from $b p-1398$ to $b p+1$, sequencing of the amplified fragments and Real Time PCR.

As shown in Table 1 patient PHTS1, affected by BRRS, had a missense mutation named c.406T $\rightarrow C$ in exon 5 of PTEN gene. This mutation, already described in the literature, determines the aminoacidic change of a cysteine residue at position 136 into an arginine [13,14]. The other two patients, PHTS2 and PHTS3 (both affected by $C S$ ), showed a significant decrease in the PTEN mRNA expression when analysed by Real Time quantitative RT-PCR (Figure 1a) (unpaired two-tailed $t$ test, confident intervals $99 \%$ p: 0,0002); this statistic result was the same when calculated with the twenty healty controls separately and with the four mixes of healty subject (data not shown). None of these patients was a carrier of a PTEN point mutation of the promoter or coding gene region, nor did they show intragenic or whole gene deletion when analysed by Real Time genomic PCR (Figure 1b). However, promoter iper-methylation cannot be excluded, and additional mechanisms could be responsible for the PTEN down-expression in these two patients. For example, point mutations in gene regions not investigated, such as intronic regions and regions at the 5' and 3' end of the gene (not included in our analysis), or mutations in other genes that could regulate PTEN expression, could be present in these patients. Using the same technique, we also performed a genomic quantification of the PTENP1 pseudogene, in light of its involvment in the PTEN messenger regulation, the quantity of which still resulted normal in all patients (Figure 1b) (unpaired two-tailed $t$

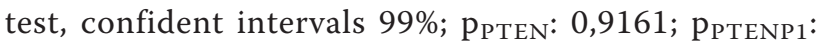
0,7755).

\section{Molecular alterations of PI3K/akt and WNT pathways are observed in non-neoplastic cells of PHTS patients}

To better clarify the patients' molecular changes associated to a germline PTEN alteration, we studied some genes related to PTEN/PI3K/AKT molecular pathway or WNT pathway, and typically involved in tumour development. Indeed, a relatively large number of studies indicate a cooperative effect of these two molecular pathways
[15]. It is already known that $\beta$-catenin phosphorylation at Ser-552, promoted by PI3K-Akt signalling, is associated with its stabilization, nuclear accumulation and transcriptional activation. Furthermore, PI3K-Akt signalling activation results in the inactivation of GSK-3 $\beta$ and reduces $\mathrm{N}$-terminal $\beta$-catenin phosphorylation, which is associated with its degradation $[16,17]$.

Thus, we performed a western blot analysis of $\beta$-catenin on protein extracted from non-neoplastic peripheral blood cells of PHTS patients and healthy subjects, to verify whether PTEN alteration causes $\beta$-catenin intracellular accumulation in these cells. As shown in Figure 2a, $\beta$-catenin is detectable by using $\mathrm{N}$-terminal antibody and phospho- $\beta$-catenin (Ser552) only in PHTS patients; total $\beta$-catenin (detected by $\mathrm{N}$-terminal antibody) is absent in all healthy controls analysed, while phospho- $\beta$-catenin (Ser552) is detected mainly in PHTS patients and gives a very faint signal in controls. The phospho- $\beta$-catenin (Ser552) accumulation favors a model whereby de-regulation of the PI3K/Akt signaling is responsabile for alteration of the $\beta$-catenin expression, while total $\beta$-catenin accumulation suggested a possible transcriptional activation of its target genes. In order to evaluate this hypothesis, we performed Real Time RT-PCR experiments for c-MYC, cycline D1 (CCND1) and COX2 messenger, classically under the control of b-catenin transcription factor. Following this, we also analysed the $A P C$ gene expression, as it is known to be the major regulator of the WNT pathway. As expected, quantification of $c M Y C$, $C C N D 1$, and $C O X 2$ messengers, conducted on RNA extracted from peripheral blood cells of the three PHTS patients and healthy subjects, revealed an mRNA overexpression of all these genes in the patients when compared with the healthy subjects - with the exception of patient PHTS3, who expresses a normal level of $c M Y C$ RNA (Figure 2b) (unpaired two-tailed $t$ test, confident intervals $\left.99 \%: \mathrm{p}_{\mathrm{cMYC}}=0,0001 ; \mathrm{p}_{\mathrm{CCND} 1}=0,0001 ; \mathrm{p}_{\mathrm{COX} 2}=0,0001\right)$. As showed in Figure $2 \mathrm{~b}$, the $A P C$ transcript resulted down-expressed only in patients PHTS2 and PHTS3 (affected by CS and carrier of PTEN mRNA downexpression), again as compared with the healthy controls (unpaired two-tailed $t$ test, confident intervals 99\%: $\mathrm{p}_{\text {APC }}$ $=0,0001)$. The relative espression values of each transcript analysed, normalised versus the glucuronidase (GUS) transcript, are reported in Figure 2b.

\section{Cytokine dysregulation is observed in non-neoplastic cells of PHTS patients}

Finally, we performed Real Time mRNA quantification of the IL10 and TNFa messengers and western blot analysis of TNFARI and TNFARII. The relative quantification of the $I L-10$ and $T N F a$ mRNA revealed statistically significant downregulation of $I L-10$ mRNA and upregulation of TNFa mRNA in PHTS patients when compared with 


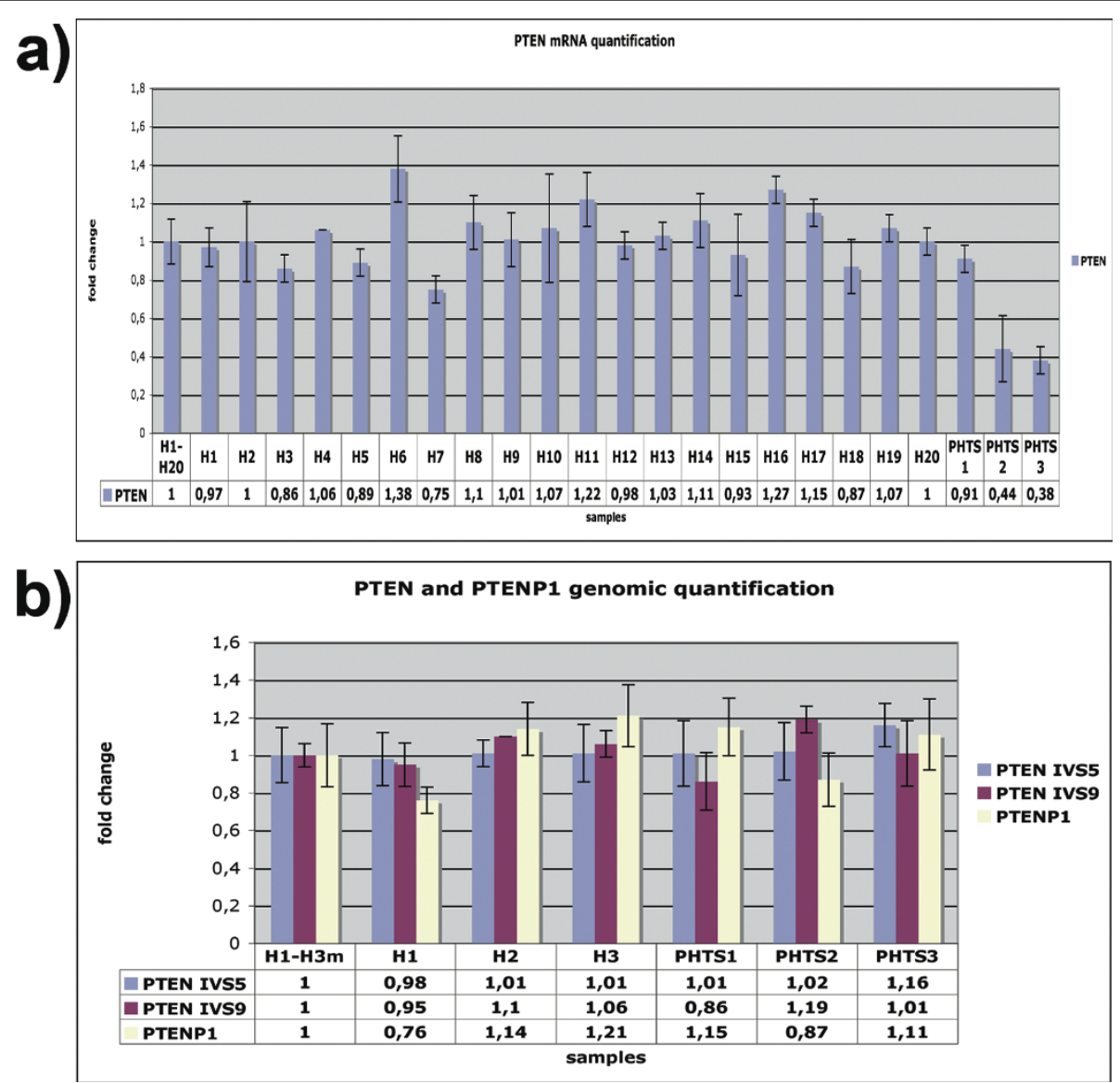

Figure 1 Alterations of PTEN gene in PHTS patients. a) Real Time PCR quantification analysis of PTEN mRNA. Real Time RT-PCR quantification analysis was performed for the PTEN messenger. $\mathrm{H}_{1-20}$ : mean value between all healthy samples used as calibrator to measure the relative expression; $\mathrm{H}_{1}, \mathrm{H}_{2}, \ldots \mathrm{H}_{20}$ : healty subject supposedly not deleted for the target genes. The graph shows quantification of the PTEN mRNA of the PHTS patients and twenty healty subjects. b) Copy number quantification of PTEN gene and PTENP1 pseudogene. Real Time PCR quantification analysis was performed for PTEN and PTENP1 genomic sequences. IVS9: amplified fragment inside intron 9 of the PTEN gene; IVS5: amplified fragment at the boundaries of exon 5 and IVS5 of the PTEN gene; PHTS1, PHTS2 and PHTS3: patients affected by PHTS syndrome, as reported in Table 1. H1, H2 and H3: three healthy subjects supposedly not deleted for the target genes.

healthy controls (Figure 3a) (unpaired two-tailed $t$ test, confident intervals 99\%: $\left.\mathrm{p}_{\mathrm{IL}-10}=0,0001 ; \mathrm{p}_{\mathrm{TNF}}=0,0001\right)$.

As shown in Figure 3b, TNFARI and TNFRII proteins were detectable mainly in the patients, in our experimental conditions. Interestingly, the main western blot signal obtained by using anti-TNFRI antibody in all three patients highlights a protein of about $25 \mathrm{Kda}$ that corresponds to the isoform $\beta$ of the TNFR1A, described by Wang et al. [18]. This isoform, generated by an alternative splicing mechanism and designated as TNFRSF1A $\beta$ [genomic sequence GenBank accession number: EU927389; protein sequence GenBank accession number: NP_001056], lacks the trans-membrane helix and the full cytoplasmic region including the DEATH domain compared to the full-length protein, while retains the signal peptide and the conserved binding domain, which corresponds to the TNFR (TNF receptor) domain [18]. We have confirmed, by RT-PCR and sequencing, that mRNA for this TNFRIA isoform was expressed in our samples (Figure $\mathrm{c}$ and $\mathrm{d}$ ).

\section{Discussion}

It is becoming increasingly evident that inflammation and cancer are intricately related. Many cancers arise from sites of infection, chronic irritation and inflammation [19-21]. Two of the key molecules mediating the inflammatory processes in tumour promotion are cytokines tumour necrosis factor- $\alpha(T N F-a)$, and IL10 [22-24]. Moreover, much data in the literature correlate TNFa expression with PTEN gene expression [25-29]. Usually, the TNF $\alpha$ induces apoptosis through TNFRI and functions related to cell survival through TNFRII. The TNF $\alpha$ binding to TNFRI activates apoptosis through two pathways, involving the adaptor proteins TNFRI-associated death domain (TRADD), and Fas associated death 


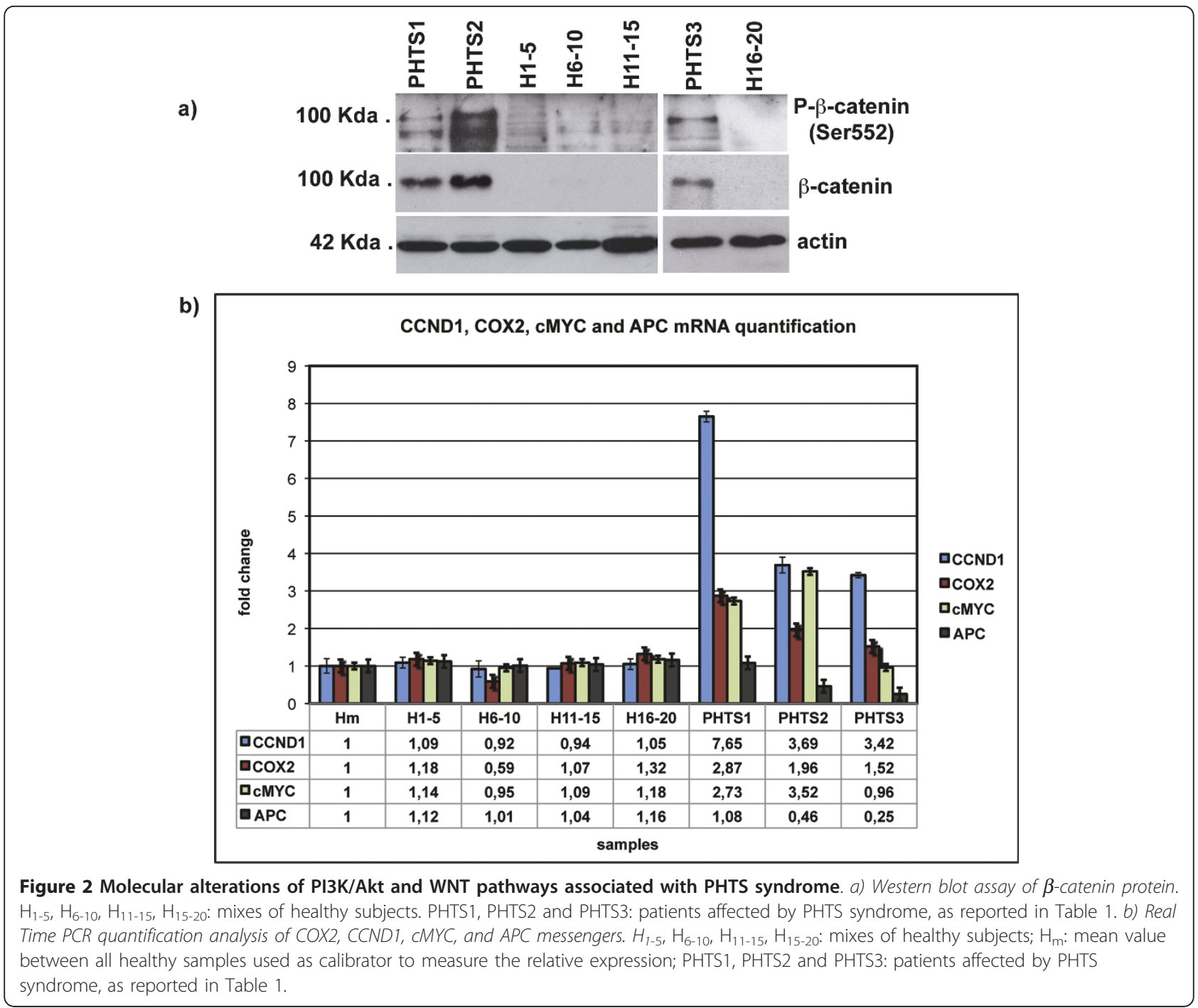

domain (FADD). By contrast, TNFRII signalling involves the mobilization and nuclear entry of the transcription factor nuclear factor $-\kappa \mathrm{B}(\mathrm{NF}-\kappa \mathrm{B})[30,31]$. However, receptor crosstalk and overlapping functions are described [31,32].

It is reasonable to hypothesize that the expression of the isoform $b$ of the TNFRIA observed in the PHTS patients could represent a mechanism by which TNFRI, lacking its DEATH domain, could shift from an apoptotic signal towards cell survival stimulation, thus inducing tumour promotion. Additional experiments are necessary to clarify the role that TNFRIA $\beta$ could play in the TNF $\alpha$ signalling.

The relationship between PI3K activation and the TNFa pathway is controversial. Evidence exists that the PI3KAkt pathway negatively regulates NF-kB and the expression of inflammatory genes [33,34], as well as that PI3K activation induces TNF $\alpha$ over-expression in different cell types $[35,36]$. This last finding are in agreement with our data. We cannot exclude that alterations of molecular pathways, such as the IL10 and TNF pathways, showed in non-neoplastc peripheral blood cells of PHTS patients are related to specific roles that PTEN plays in the nucleus, independent of the PI3K/Akt pathway [7].

These data represent the first evidence of $\beta$-catenin accumulation in non-neoplastic cells of PHTS patients, caused by germ-line PTEN alteration without a "second hit" of gene inactivation taking place. In light of these data, we suggest that $\beta$-catenin could represent a good candidate as a diagnostic marker for hereditary colorectal diseases that determine $\beta$-catenin accumulation. This is mainly noteworthy for PHTS syndrome, which is often underdiagnosed. An expansion of the current study, to be conducted on a larger population, has been planned. This should confirm the robustness of the data presented herein. 
a)

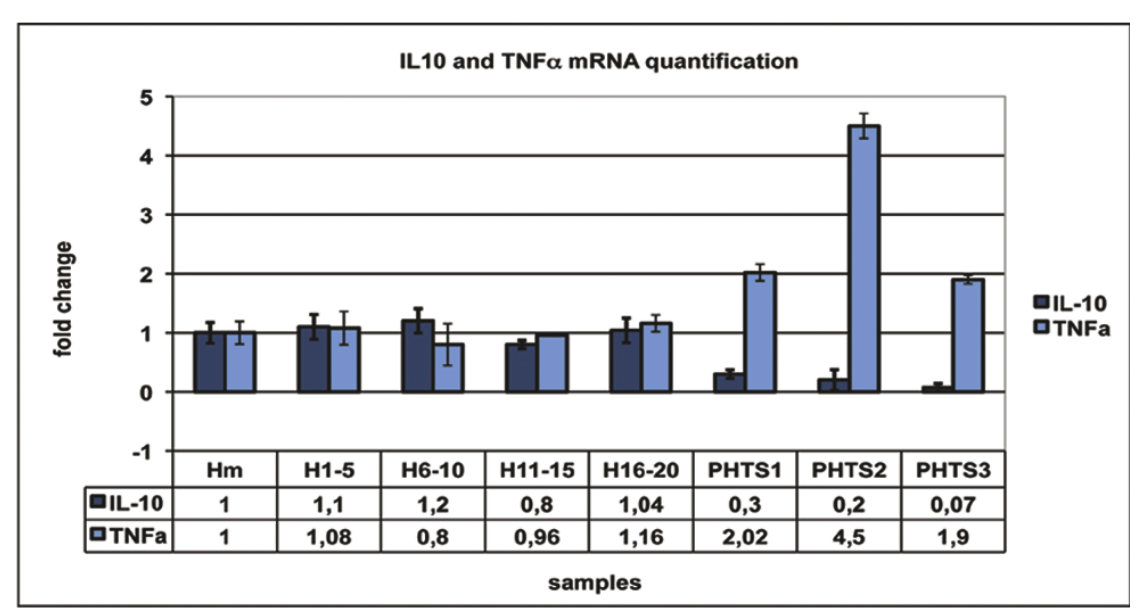

b)

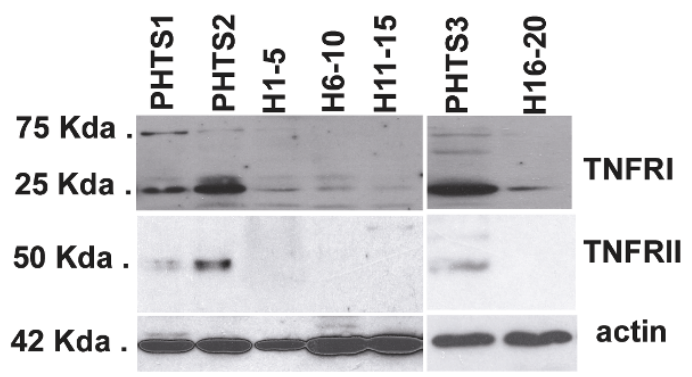

c)

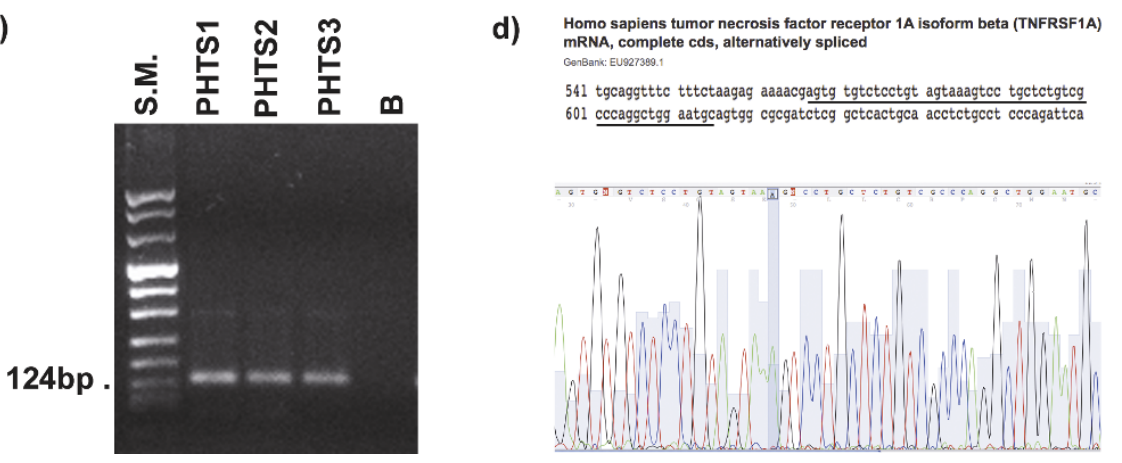

Figure 3 Cytokine disregulation on peripheral blood cells of PHTS patientsa) Real Time PCR quantification analysis of IL10 and TNF $\alpha$ mRNA. b) Western blot assay of TNFR1 and TNFR2. $\mathrm{H}_{1-5}, \mathrm{H}_{6-10}, \mathrm{H}_{11-15}, \mathrm{H}_{15-20}$ : mixes of healthy subjects; $\mathrm{H}_{m}$ : mean value between all healthy samples used as calibrator to measure the relative expression; PHTS1, PHTS2 and PHTS3: patients affected by PHTS syndrome, as reported in Table 1. C) RT-PCR analysis of the TNFRSFIA 3 isoform. S.M.: genomic molecular weight marker; B: amplified sample without CDNA template. d) sequence analysis of the amplified fragments showed in Figure 3d. The genomic sequence GenBank accession number is: EU927389. The underlined nucleotide are those showed in the electropherogram.

Overall, our data is in line with several previous studies. In human alveolar macrophages, bacterial lipopolysaccharide (LPS) exposure activates PI3-K/Akt, inactivates GSK-3 $\beta$, and causes accumulation of $\beta$-catenin in the nucleus of any cell and expression of genes that require nuclear $\beta$-catenin for their activation [37]. In human endometrial cancer cells with PTEN mutation, the PI3K/Akt survival pathway is involved in the regulation of COX-2 and PGE2 synthesis. The authors showed that Akt phosphorylation was high in mutated PTEN cells compared to wild-type PTEN cells, and that this phosphorylation 
status is associated with overexpression of $\mathrm{COX}-2$ mRNA, its protein levels, and prostaglandin E2 (PGE2) production [38]. In colorectal cancer, PTEN knockdown results in nuclear $\beta$-catenin accumulation and in increased expression of downstream proteins $c-M Y C$ and cycline D1 [28]. Moreover, Lee et al. demonstrated that, during inflammatory bowel disease, PI3K/Akt signalling cooperates with Wnt to increase $\beta$-catenin signalling, determining the progression from chronic ulcerative colitis to colitis-associated cancer [15].

In this scenario, the $A P C$ transcriptional down-regulation we have observed in peripheral blood cells of two PHTS patients, suggests an intrinsic cooperative action of PI3K/Akt and Wnt signalling to increase $\beta$-catenin intacellular concentration. Taking the latter into account, and as previously described for other tumour suppressor genes [39,40], PTEN mRNA molecular screening investigations are necessary to obtain more precise molecular diagnoses, with a view to better characterizing PHTS patients and probably to explain the PHTS cases that remain without identified molecular alterations. It is interesting that the reduced APC levels are found in the two cases that do not have a PTEN mutation identified on DNA. We can not exclude that this could be due to alternative mechanisms (possibly mutations in other genes), that cause reduction in both APC and PTEN mRNA level. Infact, though unlikely, the presence of genomic rearrangements in PHTS2 and PHTS3, cannot be completely ruled out with the methods used.

\section{Conclusion}

In conclusion, it is likely that PTEN germ-line alteration and $\beta$-catenin accumulation, observed in peripheral blood cells of PHTS patients, could determine a cell survival and pro-inflammatory stimulation mediated by the expression of molecules such as COX2, CCND1 and $T N F a$ receptors. Increased levels of messengers cMYC and CCND1 are often observed in different tumour types, such as breast cancer, endometrial cancer, thyroid cancer and ovarian cancer [41-43]. Interestingly, these types of tumours correspond to the neoplasias most frequently associated to PHTS syndrome. It is likely that the overexpression of mRNA of cMYC and CCND1 in non neoplastic cells of PHTS patients puts them at hight risk of developing these types of tumours.

The data presented herein are in agreement with and reinforces the results of Alimonti et al. [10], who propose a new "continuum model" for cancer initiation and promotion for the PTEN tumour suppressor gene, resulting from the subtle reduction in a tumour suppressor gene without requiring an additional genetic hit at that locus. In their model, tumours initiated by a subtle downregulation of a tumour suppressor gene can progress in the absence of $\mathrm{LOH}$ of the wild type allele [10].

Knowledge of specific molecular pathways changes downstream of PTEN alteration could be helpful in optimizing molecular targeted therapy and preventative care, not only for PHTS patients, but mainly because PTEN mutations are involved in a wide range of human diseases and cancers.

\section{Abbreviations}

PI3K: Phosphatidylinositol 3-kinase; AKT: Protein kinase B-alpha; mTOR: Mammalian target of rapamycin; WNT: wingless-type MMTV integration site family; cMYC: V-myc avian myelocytomatosis viral oncogene homolog; CCND1: Cycline D1; COX2: Cyclooxygenase 2; APC: Adenomatous polyposis coli; TNF-a: Tumor necrosis factor alpha; TNFRI: Tumor necrosis factor receptor superfamily member $1 \mathrm{~A}$; TNFRII: Tumor necrosis factor receptor superfamily member 1B; IL-10: Interleukin 10.

\section{Acknowledgements}

This study was supported by a grant from Ministero Salute - Ricerca Oncologica - RECAM-2006-353005; PRIN 2007-prot. 2007EN8F7T-004; Convenzione CEINGE-Regione Campania. We thank Annamaria Staiano and Massimo Santoro for critical reading of the manuscript. We report no conflicts of interest.

\section{Author details}

${ }^{1}$ Dipartimento di Biochimica e Biotecnologie Mediche and CEINGE Biotecnologie Avanzate, Università di Napoli Federico II, via S. Pansini 5, Naples 80131, Italy. ²Dipartimento di Biologia Strutturale e Funzionale, Università di Napoli Federico II, Complesso Universitario Monte S. Angelo, Via Cinthia, Naples 80126, Italy. ${ }^{3}$ Istituto Nazionale dei Tumori - Fondazione G. Pascale, via M. Semmola, Naples 80131, Italy.

\section{Authors' contributions}

MDR: designed and processed the study, interpreted the data and wrote the first draft of the manuscript; performed statistical analysis and study supervision; conceived and supervised the study. MG: contributed in Real Time PCR experiment. LP and FD: contributed in PCR and sequencing. MT: contributed on western Blot; GBR: was responsible for endoscopy and clinical diagnosis of the patients; PI: critically evaluated the study and manuscript revision; obtained funding. All authors read and approved the final manuscript.

\section{Competing interests}

The authors declare that they have no competing interests.

Received: 21 September 2011 Accepted: 20 April 2012 Published: 20 April 2012

\section{References}

1. Manfredi M: Hereditary hamartomatous polyposis syndromes: understanding the disease risks as children reach adulthood. Gastroenterol Hepatol 2010, 6(3):185-196.

2. Heald B, Mester J, Rybicki L, Orloff MS, Burke CA, Eng C: Frequent gastrointestinal polyps and colorectal adenocarcinomas in a prospective series of PTEN mutation carriers. Gastroenterology 2010, 139(6):1927-1933.

3. Farooq A, Walker $L$, Bowling J, Audisio RA: Cowden syndrome. Cancer Treat Rev 2010, 36(8):577-583.

4. Eng C: PTEN: one gene, many syndromes. Human Mutat 2003, 22:183-198.

5. Pilarski $R$, Eng C: Will the real Cowden syndrome please stand up (again)? Expanding mutational and clinical spectra of the PTEN hamartoma tumour syndrome. J Med Genet 2004, 41(5):323-326.

6. Waite KA, Eng C: Protein PTEN: form and function. Am J Human Genet 2002, 70(4):829-844.

7. Song MS, Carracedo A, Salmena L, Song SJ, Egia A, Malumbres M, Pandolfi PP: Nuclear PTEN regulates the APC-CDH1 tumor-suppressive 
complex in a phosphatase-independent manner. Cell 2011, 144(2):187-199.

8. Poliseno L, Salmena L, Zhang J, Carver B, Haveman WJ, Pandolfi PP: A coding-independent function of gene and pseudogene mRNAs regulates tumour biology. Nature 2010, 465(7301):1033-1038.

9. Salmena L, Carracedo A, Pandolfi PP: Tenets of PTEN tumor suppression. Cell 2008, 133:403-414

10. Alimonti A, Carracedo A, Clohessy JG, Trotman LC, Nardella C, Egia A, Salmena L, Sampieri K, Haveman WJ, Brogi E, Richardson AL, Zhang J, Pandolfi PP: Subtle variations in Pten dose determine cancer susceptibility. Nat Genet 2010, 42(5):454-458.

11. Larsen Haidle J, Howe JR: Juvenile Polyposis Syndrome. GeneReviews Seattle (WA): University of Washington, Seattle; 2003, [updated 2011 Sep 29].

12. Kay PS, Soetikno RM, Mindelzun R: Young HS Diffuse esophageal glycogenic acanthosis: an endoscopic marker of Cowden's disease. Am J Gastroenterol 1997, 92(6):1038-1409.

13. Kubo $Y$, Urano $Y$, Hida $Y$, Ikeuchi $T$, Nomoto $M$, Kunitomo $K$, Arase S: A novel PTEN mutation in a Japanese patient with Cowden disease. $\mathrm{Br} J$ Dermatol 2000, 142(6):1100-1105.

14. Jenny B, Radovanovic I, Haenggeli CA, Delavelle J, Rüfenacht D, Kaelin A, Blouin JL, Bottani A, Rilliet B: Association of multiple vertebral hemangiomas and severe paraparesis in a patient with a PTEN hamartoma tumor syndrome. Case report. J Neurosurg 2007, 107:307-313.

15. Lee G, Goretsky T, Managlia E, Dirisina R, Singh AP, Brown JB, May R, Yang GY, Ragheb JW, Evers BM, Weber CR, Turner JR, He XC, Katzman RB, Li L, Barrett TA: Phosphoinositide 3-kinase signaling mediates betacatenin activation in intestinal epithelial stem and progenitor cells in colitis. Gastroenterology 2010, 139(3):869-881, 881.e1-9.

16. He XC, Yin T, Grindley JC, Tian Q, Sato T, Tao WA, Dirisina R, PorterWestpfahl KS, Hembree M, Johnson T, Wiedemann LM, Barrett TA, Hood L, Wu H, Li L: PTEN-deficient intestinal stem cells initiate intestinal polyposis. Nat Genet 2007, 39:189-198.

17. Fang D, Hawke D, Zheng Y, Xia Y, Meisenhelder J, Nika H, Mills GB, Kobayashi R, Hunter T, Lu Z: Phosphorylation of beta-catenin by AKT promotes beta-catenin transcriptional activity. J Biol Chem 2007, 282:11221-11229.

18. Wang $P, Y u$ P, Gao P, Shi T, Ma D: Discovery of novel human transcript variants by analysis of intronic single-block EST with polyadenylation site. BMC Genomics 2009, 10:518.

19. Covey TM, Edes K, Coombs GS, Virshup DM, Fitzpatrick FA: Alkylation of the tumor suppressor PTEN activates Akt and $\beta$-catenin signaling: a mechanism linking inflammation and oxidative stress with cancer. PLOS One 2010, 5(10):e13545.

20. Medzhitov R: Origin and physiological roles of inflammation. Nature 2008, 454:428-435

21. Sheehan KM, Sheahan K, O'Donoghue DP, MacSweeney F, Conroy RM, Fitzgerald DJ, Murray FE: The relationship between cyclooxygenase-2 expression and colorectal cancer. Jama 1999, 282:1254-1257.

22. Szlosarek P, Charles KA, Balkwill FR: Tumour necrosis factor-a as a tumour promoter. Eur J Cancer 2006, 42(6):745-750.

23. Terzić J, Grivennikov S, Karin E, Karin M: Inflammation and colon cancer. Gastroenterology 2010, 138(6):2101-2114, e5.

24. Sturlan S, Oberhuber G, Beinhauer BG, Tichy B, Kappel S, Wang J, Rogy MA: Interleukin-10-deficient mice and inflammatory bowel disease associated cancer development. Carcinogenesis 2001, 22:665-671.

25. Kim S, Domon-Dell C, Kang J, Chung DH, Freund JN, Evers BM: Downregulation of the tumor suppressor PTEN by the tumor necrosis factoralpha/nuclear factor-kappaB (NF-kappaB)-inducing kinase/NF-kappaB pathway is linked to a default lkappaB-alpha autoregulatory loop. Biol Chem 2004, 279(6):4285-4291.

26. Kim NH, Jeon S, Lee HJ, Lee AY: Impaired PI3K/Akt activation-mediated NF-kappaB inactivation under elevated TNF-alpha is more vulnerable to apoptosis in vitiliginous keratinocytes. J Invest Dermatol 2007, 127(11):2612-2617.

27. Zhang A, Wang Y, Ye Z, Xie H, Zhou L, Zheng S: Mechanism of TNF-ainduced migration and hepatocyte growth factor production in human mesenchymal stem cells. J Cell Biochem 2010, 111(2):469-475.

28. Bowen KA, Doan HQ, Zhou BP, Wang Q, Zhou Y, Rychahou PG, Evers BM: PTEN loss induces epithelial-mesenchymal transition in human colon cancer cells. Anticancer Res 2009, 29(11):4439-4449.
29. Lee YR, Yu HN, Noh EM, Youn HJ, Song EK, Han MK, Park CS, Kim BS, Park YS, Park BK, Lee SH, Kim JS: TNF-alpha upregulates PTEN via NFkappaB signaling pathways in human leukemic cells. Exp Mol Med 2007, 39(1):121-127.

30. Zidi I, Mestiri S, Bartegi A, Amor NB: TNF-alpha and its inhibitors in cancer. Med Oncol 2010, 27(2):185-198.

31. Faustman D, Davis M: TNF receptor 2 pathway: drug target for autoimmune diseases. Nat Rev Drug Discov 2010, 9(6):482-493.

32. Pimentel-Muiños FX, Seed B: Regulated commitment of TNF receptor signaling: a molecular switch for death or activation. Immunity 1999, 11(6):783-793.

33. Guha M, Mackman N: The phosphatidylinositol 3-kinase-Akt pathway limits lipopolysaccharide activation of signaling pathways and expression of inflammatory mediators in human monocytic cells. J Biol Chem 2002, 277(35):32124-32132.

34. Martin M, Rehani K, Jope RS, Michalek SM: Toll-like receptor-mediated cytokine production is differentially regulated by glycogen synthase kinase 3. Nat Immunol 2005, 6(8):777-784

35. Hwang MK, Song NR, Kang NJ, Lee KW, Lee HJ: Activation of phosphatidylinositol 3-kinase is required for tumor necrosis factor-alphainduced upregulation of matrix metalloproteinase-9: its direct inhibition by quercetin. Int J Biochem Cell Biol 2009, 41(7):1592-1600.

36. Qiu L, Zhang L, Zhu L, Yang D, Li Z, Qin K, Mi X: PI3K/Akt mediates expression of TNF-alpha mRNA and activation of NF-kappaB in calyculin A-treated primary osteoblasts. Oral Dis 2008, 14(8):727-733.

37. Monick MM, Carter AB, Robeff PK, Flaherty DM, Peterson MW Hunninghake GW: Lipopolysaccharide activates Akt in human alveolar macrophages resulting in nuclear accumulation and transcriptional activity of beta-catenin. J Immunol 2001, 166(7):4713-4720.

38. St-Germain ME, Gagnon V, Mathieu I, Parent S, Asselin E: Akt regulates COX-2 mRNA and protein expression in mutated-PTEN human endometrial cancer cells. Int J Oncol 2004, 24(5):1311-1324.

39. De Rosa M, Galatola M, Borriello S, Duraturo F, Masone S, Izzo P: Implication of adenomatous polyposis coli and MUTYH mutations in familial colorectal polyposis. Dis Colon Rectum 2009, 52(2):268-674.

40. De Rosa M, Galatola M, Quaglietta L, Miele E, De Palma G, Rossi GB, Staiano A, Izzo P: Alu-mediated genomic deletion of the serine/threonine protein kinase 11 (STK11) gene in Peutz-Jeghers syndrome. Gastroenterology 2010, 138(7):2558-2560.

41. Wang $Y$, Thakur A, Sun Y, Wu J, Biliran H, Bollig A, Liao DJ: Synergistic effect of cyclin D1 and c-Myc leads to more aggressive and invasive mammary tumors in severe combined immunodeficient mice. Cancer Res 2007, 67(8):3698-3707.

42. Castellone MD, De Falco V, Rao DM, Bellelli R, Muthu M, Basolo F, Fusco A, Gutkind JS, Santoro M: The beta-catenin axis integrates multiple signals downstream from RET/papillary thyroid carcinoma leading to cell proliferation. Cancer Res 2009, 69(5):1867-1876.

43. Chien J, Narita K, Rattan R, Giri S, Shridhar R, Staub J, Beleford D, Lai J, Roberts LR, Molina J, Kaufmann SH, Prendergast GC, Shridhar V: A role for candidate tumor-suppressor gene TCEAL7 in the regulation of c-Myc activity, cyclin D1 levels and cellular transformation. Oncogene 2008, 27(58):7223-7234.

Pre-publication history

The pre-publication history for this paper can be accessed here: http://www.biomedcentral.com/1471-2350/13/28/prepub

doi:10.1186/1471-2350-13-28

Cite this article as: Galatola et al: Beta catenin and cytokine pathway dysregulation in patients with manifestations of the "PTEN hamartoma tumor syndrome". BMC Medical Genetics 2012 13:28. 